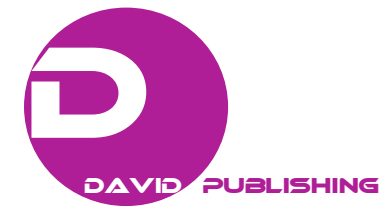

\title{
Simulation of Energy Consumption of Machine Tool Motion for 3-Axis Machining
}

\author{
Akio Hayashi ${ }^{1}$, Zen Kimura ${ }^{2}$ and Yohichi Nakao ${ }^{1}$ \\ 1. Department of Mechanical Engineering, Kanagawa University, 3-27-1, Rokkaku-bashi, Kanagawa-ku, Yokohama 221-8686, Japan \\ 2. Department of Mechanical Engineering, Graduate School of Kanagawa University, 3-27-1, Rokkaku-bashi, Kanagawa-ku, \\ Yokohama 221-8686, Japan
}

Received: September 27, 2016 / Accepted: October 11, 2016 / Published: January 31, 2017.

\begin{abstract}
In recent years, the shortage of the energy source is a serious problem in the world. Thus, the reduction of the energy consumption in manufacturing fields has been demanded. The energy consumption of NC machine tools has been also focused on. However, the energy consumption of the machine tool motion of each control axis during machining process has not been considered. In this study, we focus on the energy consumption during the machining process and we proposed the simulation model of the energy consumption of the feed drive systems of NC machine tool. Based on the proposed model, the energy consumption during the machining motion was simulated and evaluated. From these results, if the CAD/CAM systems can generate the tool paths considering about the energy consumption of NC machine tools, the energy consumption will be reduced without replacing or overhaul the machine tools.
\end{abstract}

Key words: Energy consumption, machine tools, tool path, CAD/CAM.

\section{Nomenclature}

$\theta \quad$ Rotation angle of the motor

$T \quad$ Motor torque

$J \quad$ Total moment of inertia about the motor axis

$K \quad$ Stiffness of the ball screw

$c_{i} \quad$ Internal damping coefficient of the ball screw

$c_{b} \quad$ Viscous damping coefficient between the ball

$c_{b} \quad$ screw and the nut

$f_{b} \quad$ Coulomb friction torque between the ball screw

and the nut

$x \quad$ Displacement of the table

$M \quad$ Drive mass

Viscous damping coefficient between the table and the guide way

Coulomb friction force between the table and the guide way

Lead of the ball screw

Power consumption of the motor

Position proportional gain

Velocity proportional gain

Velocity integral gain

Corresponding author: Akio Hayashi, assistant professor, research fields: machine tools, CAD/CAM.

\section{Introduction}

In recent years, the energy saving has been promoted in various fields, because the shortage of energy sources is a serious problem in the world. In particular, vast amounts of energy have been consumed in manufacturing fields. Thus, the reduction of energy consumption in the manufacturing field is required. From this point of view, the energy consumption in manufacturing systems and machine tools has been measured and investigated by many researchers [1-7]. For example, Lee et al. [3] developed an energy model of a machine tool and estimated the total energy consumption of variable machine tools by decoupling the cutting power. Mori et al. [5] measured the energy efficiency during machining. Avram and Xirouchakis [6] estimated the energy consumption of the spindle and feed axes during 2.5D machining for variable cutting conditions.

On the other hand, we have presented that the energy consumption of NC machine tools changes by the difference of the feed speed and the motion 
direction in previous studies [8]. Accordingly, it is expected that the energy consumption during the machining process can be reduced by considering the motion of each axis in a machine tool.

However, current commercialized CAD/CAM systems do not consider the energy consumption when it generates the tool paths. If the CAD/CAM systems can generate the tool paths considering the energy consumption for the motion of NC machine tools, the energy consumption will be reduced without replacing or overhaul the machine tools.

The goal of this study is to develop a tool path generation system that takes into consideration the energy consumption for the motion of each axis in NC machine tools. Thus, we propose the simulation model of the energy consumption of the feed drive systems of NC machine tool. In addition, the parameters in the proposed model were determined experimentally and through calculation based on the design values of the machine tool. Then, it is shown that the simulation model can simulate the power consumption of the feed motion in each control axis.

Furthermore, in order to verify the proposed model, the simulation tests are carried out with the tool path for three-control axis machine tool motion. Then, the simulation result of the energy consumption for the motion of NC machine tool axis is compared with the measurement result.

Next, the energy consumption on the various tool paths was simulated by the proposed model. As the result, it was shown that the energy consumption is significantly different by the difference of the tool paths even if same part shape is machined. Finally, based on the simulation model, we consider the influential factors to generate tool paths for reducing the energy consumption of the machine tool motions.

\section{Simulation Model of Power Consumption of Feed Drive System of NC Machine Tools}

\subsection{Modeling of Feed Drive System in Machine Tool}

A schematic diagram of a machine tool for measurement tests of the power consumption is shown in Fig. 1. This machine tool has three control liner axes (X, Y and Z-axis). $\mathrm{X}$-axis consists on the $\mathrm{Y}$-axis and $\mathrm{Z}$-axis is independent. In addition, the feed drive mechanism of liner axis using a ball screw is modeled as shown in Fig. 2. In the model, the coulomb and the viscous frictions between the table and guide way are considered (as symbol $f_{t}$ and $c_{t}$ in Fig. 2). In addition, the coulombs and the viscous friction between the ball screw and the nut are also considered (as symbol $f_{b}$ and $c_{b}$ in Fig. 2).

Based on the model of the drive mechanism of machine tool, the equation of motion of the motor can be derived as Eq. (1). In addition, the equation of motion of the table is also derived as Eq. (2).

$$
\begin{array}{r}
T=J \ddot{\theta}+c_{b} \dot{\theta}+\frac{L}{2 \pi} K\left(\frac{L}{2 \pi} \theta-x\right)+\frac{L}{2 \pi} c_{i}\left(\frac{L}{2 \pi} \dot{\theta}-\dot{x}\right)+f_{b} \\
0=M \ddot{x}+c_{t} \dot{x}-K\left(\frac{L}{2 \pi} \theta-x\right)-c_{i}\left(\frac{L}{2 \pi} \dot{\theta}-\dot{x}\right)+f_{t}
\end{array}
$$

Then, the control system is added to the feed drive mechanism, the block diagram is depicted as shown in Fig. 3. Here, the power consumption of the motor of

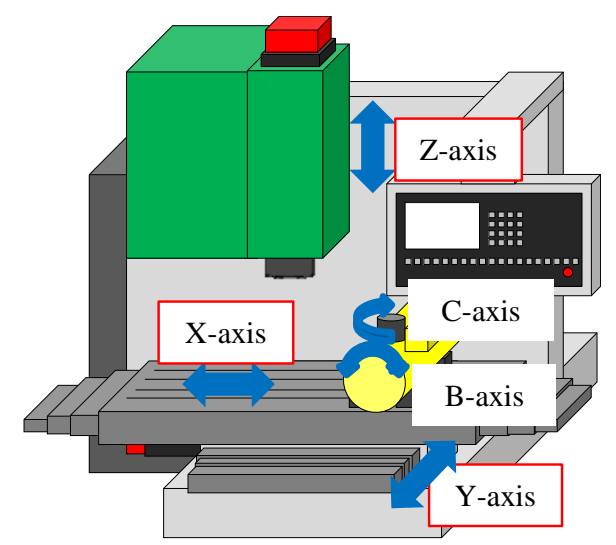

Fig. 1 Schematic diagram of machine tool.

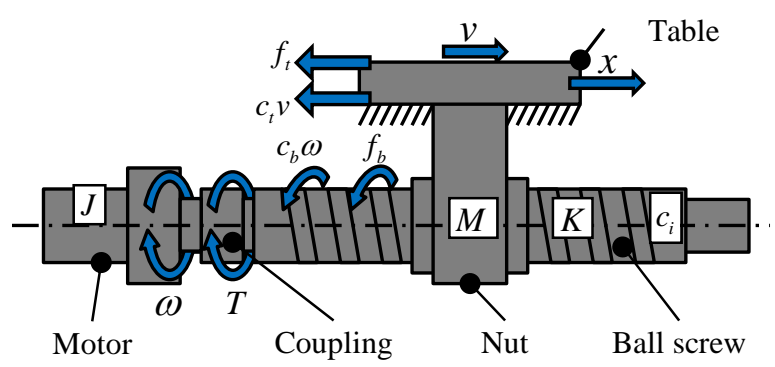

Fig. 2 Model of feed drive mechanism by ball screw. 


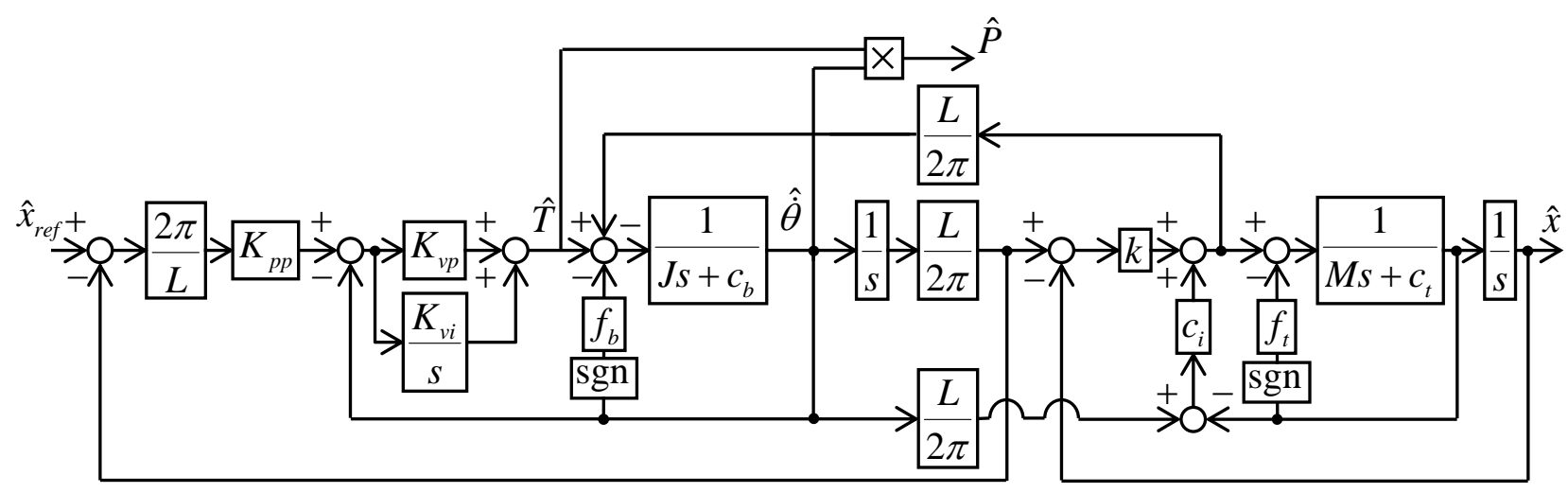

Fig. 3 Block diagram of feed drive system of linear axis.

the each axis is assumed to be equal to the motor power. Thus, the power consumption is calculated from the multiplication of the motor torque $T$ and the angular velocity $\omega$ as Eq. (3).

$$
P=T \times \omega
$$

The coulomb and viscous frictions in the mathematical model were determined based on the measurement results for the motor torque. In Eqs. (1) and (2), acceleration $\ddot{x}$ and angular acceleration $\ddot{\theta}$ become 0 during uniform motion. Thus, the motor torque can be derived following Eq. (4).

$$
T=\left(c_{b} \dot{\theta}+\frac{L}{2 \pi} c_{t} \dot{x}\right)+\left(f_{b}+\frac{L}{2 \pi} f_{t}\right)=C \dot{x}+F
$$

In Eq. (4), $\dot{x}$ is the feed rate of the table. In addition, $F$ is the total of the coulombs friction and $C$ is the total of viscous damping coefficients.

The motor torque of each axis was measured during linear uniform motion at various feed rates of from $100 \mathrm{~mm} / \mathrm{min}$ to $2,000 \mathrm{~mm} / \mathrm{min}$. Fig. 4 shows the measurement results of the motor torque of the $\mathrm{X}$-axis. The approximation line in Fig. 4 shows the relationship between the velocity and the motor torque based on the measurement results. Thus, the intercept of the approximation line indicates the coulomb friction force, and the gradient of the approximation line indicates the viscous damping coefficient as shown in Eq. (4). However, the friction force from the measurement results is the total of the coulombs friction $F$, and the viscous damping coefficients $C$ as shown in Eq. (4), Therefore, it is impossible to identify viscous damping coefficients $c_{t}$, and $c_{b}$ and coulomb frictions $f_{t}$ and $f_{b}$ separately. Thus, each coulombs and viscous damping coefficient was dividing equally in this model [9].

The power consumption of the servo motor is influenced by the torque due to the friction force for the axis. In addition, the frictional force is considered to vary depending on various factors, such as temperature change. However, the proposed model does not consider the temperature change in the machine tool because no significant difference in the energy consumption was observed among the tool path operations.

The parameters in the mathematical model such as the mass, the inertia and the stiffness of each axis were calculated from the size of the CAD model of the machine tool.

\subsection{Measurement and Simulation Tests of Power} Consumption of Feed Drive System in Machine Tool

The measurement tests of the power consumption of three linear control axes were carried out. Fig. 5

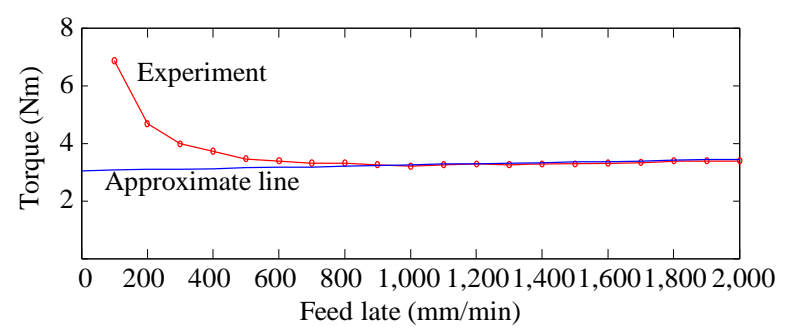

Fig. 4 Measurement result of motor torque with each feed rate. 


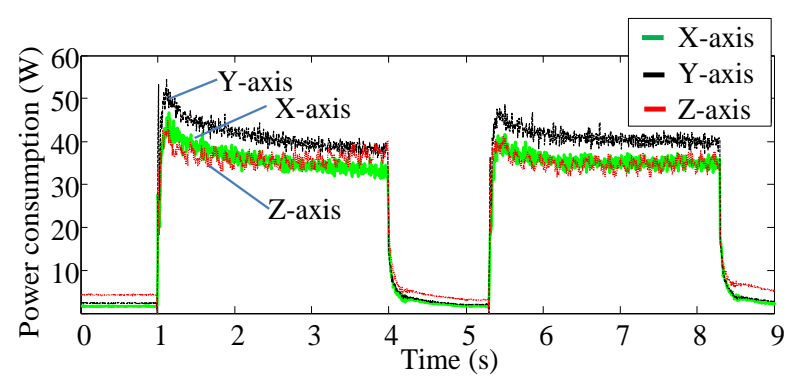

Fig. 5 Power consumption of each axis during reciprocal motion.

shows the measurement results of the power consumption during the linear reciprocal motion with the feed rate of $1,000 \mathrm{~mm} / \mathrm{min}$. The total distance of the motion is $100 \mathrm{~mm}$. From Fig. 5, the Y-axis consumed the biggest power in three linear axes since the mass of the $\mathrm{Y}$-axis is the biggest. On the other hand, the power consumption of the $\mathrm{X}$ and $\mathrm{Z}$ axis was nearly the same.

Then, the power consumption was simulated by the proposed model. The each control axis of the machine tool was reciprocated with the feed rate of $1,000 \mathrm{~mm} / \mathrm{min}$ and 2,000 $\mathrm{mm} / \mathrm{min}$. Fig. 6 shows the comparison results of the measurement and simulation results of the power consumption of each control axis.

As the results, it can be seen that the simulation model can estimate the power consumption during reciprocal motion. However, the power consumption at the acceleration was not simulated correctly. The reason of these results is that the controller gain in the mathematical model is different from actual parameter of the NC controller.

\section{Evaluation of Energy Consumption During Machine Tool Operation}

\subsection{Tool Path and Energy Consumption for Machining of Hemisphere}

Tool paths were generated for machining a hemispherical product by current CAD/CAM system. Fig. 7 shows the machining process of a hemisphere from a cube workpiece. Figs. 7a-7c show the roughing process, Figs. $7 \mathrm{~d}$ and $7 \mathrm{e}$ are the finishing process.

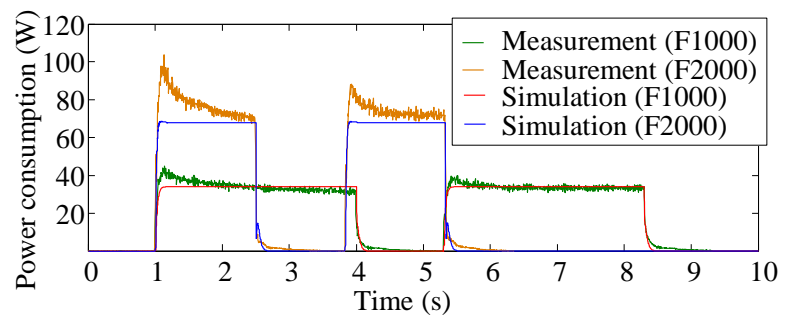

(a) $\mathrm{X}$-axis
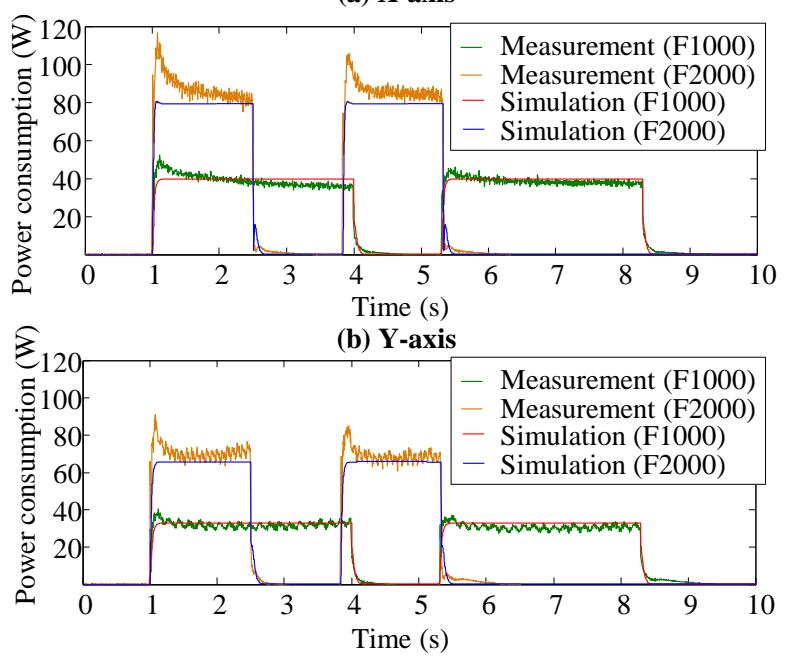

(c) Z-axis

Fig. 6 Measurement and simulation results of power consumption for each axis.

The radius of the hemisphere is $20 \mathrm{~mm}$ and the workpiece is the cube of $50 \times 50 \times 40 \mathrm{~mm}$. The assumed cutting condition is that the tool type is a ball endmill and the feed rate is set to be $1,000 \mathrm{~mm} / \mathrm{min}$.

Then, the measurement tests of the power consumption for the motion in all process were carried out. In addition, the power consumption was simulated by the proposed model.

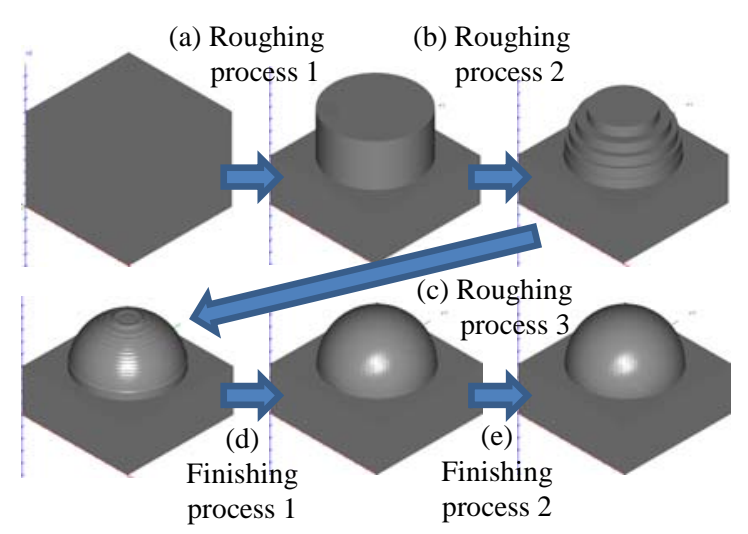

Fig. 7 Measurement result of motor torque with each feed rate. 


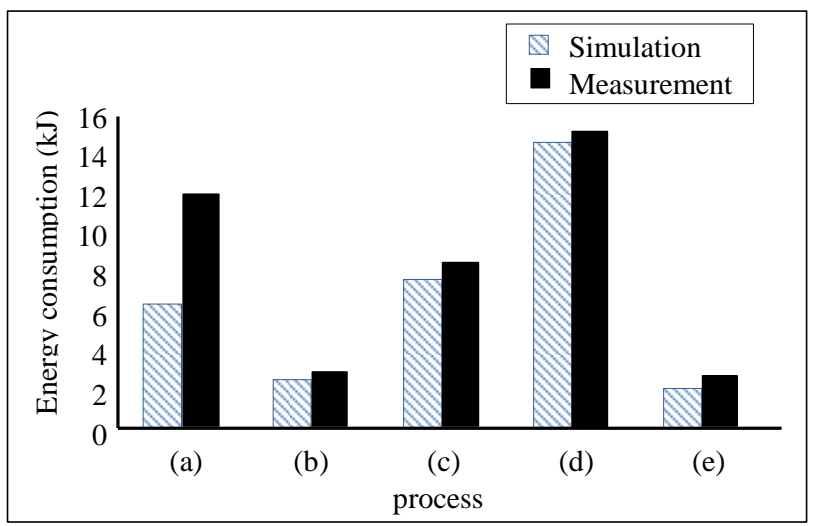

Fig. 8 Measurement and simulation results of energy consumption for each process.

Then, the energy consumption was calculated by time integral of the simulation and measurement results of the power consumption of each axis. Fig. 8 shows the comparison results of the simulation and measurement results of the total energy consumption in each process. From this result, the predictions of the energy consumption are fairly well. However, in case of the contour machining, the simulated energy consumption is much smaller than the measured results. The path in a first roughing process as shown in Fig. 8a took the longest motion time, thus it is thought that an error due to the waiting power consumption is large.

\subsection{Evaluation of Energy Consumption by Difference of Tool Path}

In order to evaluate the difference of the energy consumption due to the machining motion in various tool paths, the tool path for medium roughing process as shown in Fig. 7c was changed to three types of paths. The generated three tool paths considered herein are shown in Fig. 9. In this case study, the feed rate was set to be $1,000 \mathrm{~mm} / \mathrm{min}$. In addition, the machining time was set to be the same for all three tool paths by changing the cutting pitch and the angle pitch of the tool. The power consumption for each of the three linear axes of the machine tool was measured during machining motion on each tool path.

In addition, the power consumption was also simulated by the proposed model. The simulation and

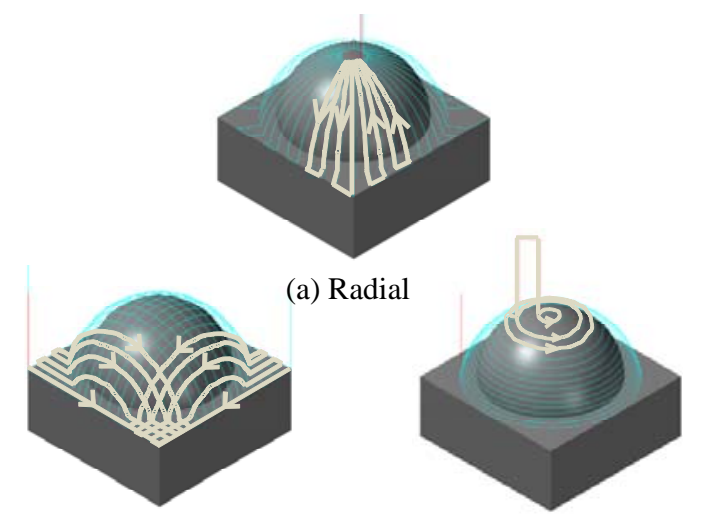

(b) Scan line

(c) Contour line

Fig. 9 Tool paths for simulation and measurement tests of energy consumption.

measurement results of the power consumption of each linear axis are shown in Figs. 10-12. From these figures, it can be seen that the proposed model can estimate the power consumption for the motion of the each axis on each tool path.

In the radial tool path, the hemisphere was machined from top to bottom along the sphere, and the power consumption changes periodically as shown in Fig. 10.

In the scan line path, the Y-axis consumed the power consumption during the second half of the process mainly as shown in Fig. 11b, because the tool moves along the $\mathrm{X}$-axis during the first half of the
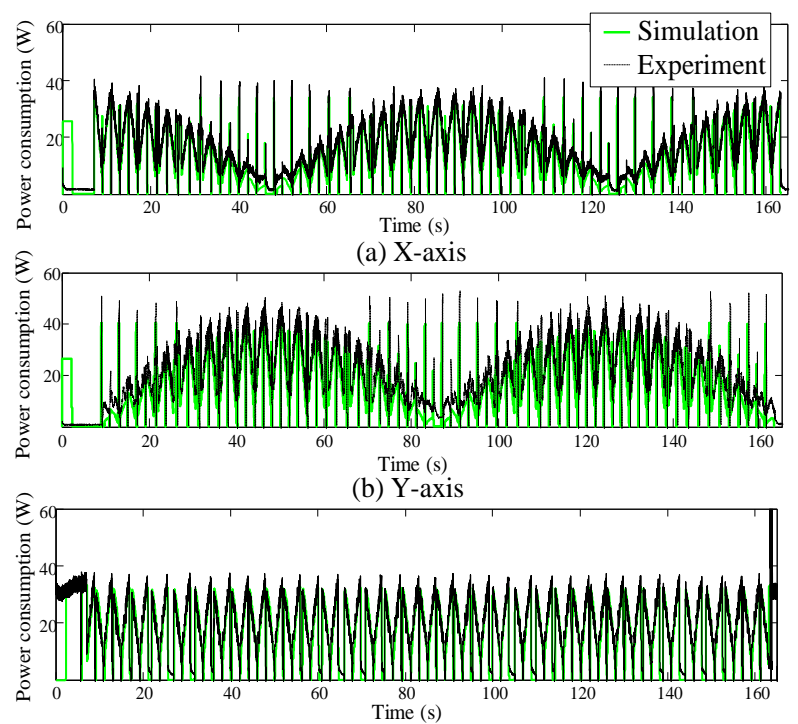

(c) Z-axis

Fig. 10 Measurement and simulation result of power consumption of each axis on radial tool path. 


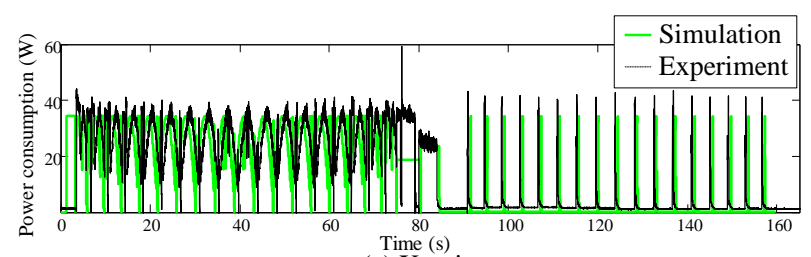

(a) X-axis

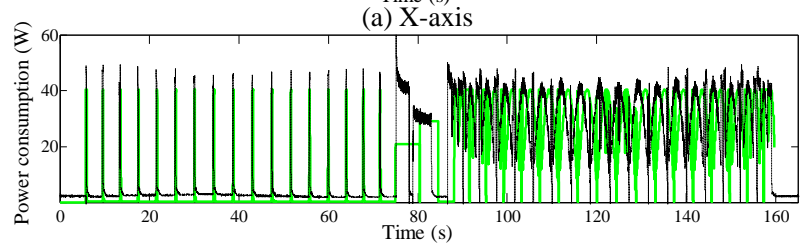

(b) Y-axis

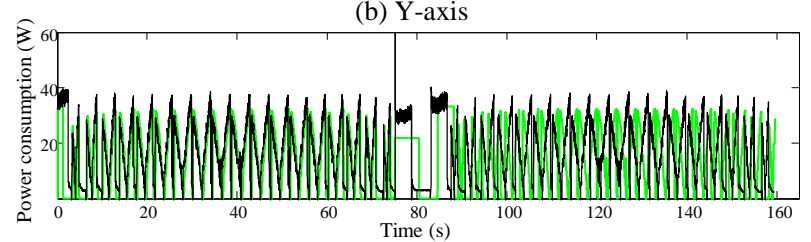

(c) Z-axis

Fig. 11 Measurement and simulation result of power consumption of each axis on scan line tool path.

process and then moves along the $\mathrm{Y}$-axis during the second half of the process.

As the results in the contour line path as shown in Fig. 12, the hemisphere was machined along the outer periphery starting from the top. Therefore, the $\mathrm{Y}$-axis always moved in a circular motion and it consumed the most power during this process.

Then, the energy consumption for each tool path was calculated by integrating the power consumption. Fig. 13 shows the energy consumption for each axis and the total energy consumption during machining for each tool path. In addition, Table 1 shows the motion time for each axis and the machining time for each tool path.

As shown in Table 1, the total machining time was the same for all paths. However, the motion time for each axis was different because the distance traveled along each axis differed depending on the tool path. Moreover, the total motion time for each axis was longer than the total machining time. Thus, even when the same product is machined, the energy consumption may differ according to the tool path.

In addition, the simulated power consumption was smaller than the measured power consumption. The reason for this is that the proposed model cannot

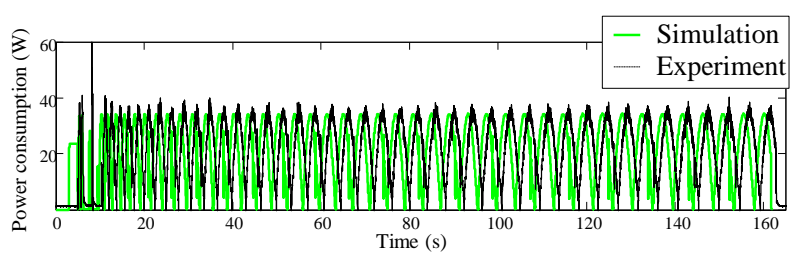

(a) X-axis

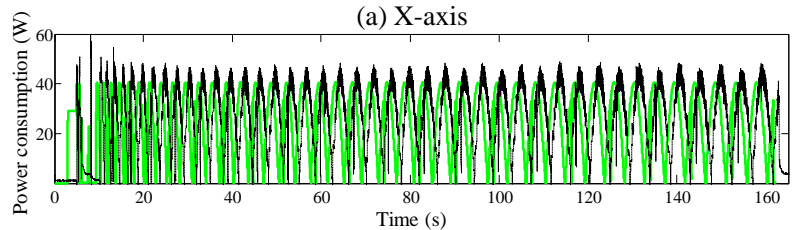

(b) $\mathrm{Y}$-axis

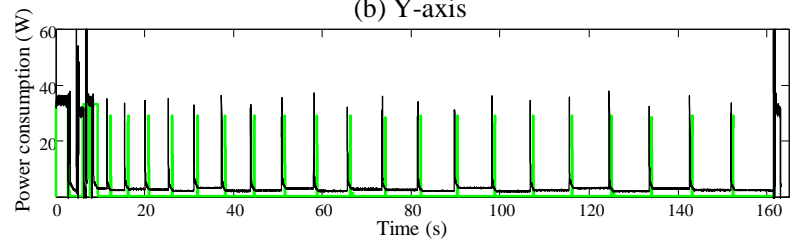

(c) Z-axis

Fig. 12 Measurement and simulation result of power consumption of each axis on contour line tool path.

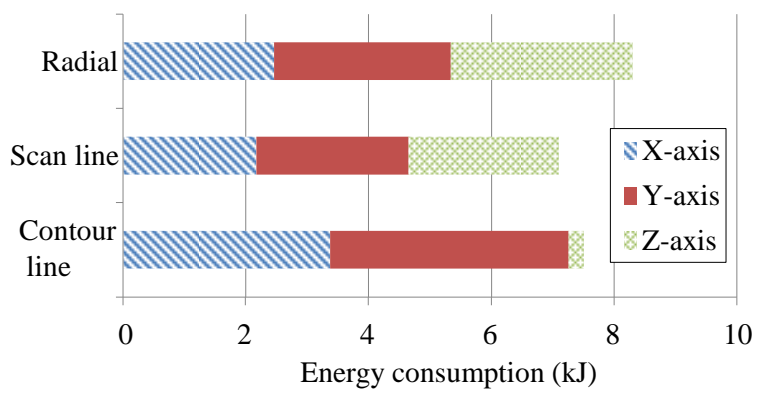

Fig. 13 Comparison of energy consumption on each tool path.

Table 1 Motion time of each axis for three types of tool path.

\begin{tabular}{lllll}
\hline $\begin{array}{l}\text { Tool path } \\
\text { type }\end{array}$ & $\begin{array}{l}\text { Motion } \\
\text { time of } \\
\text { X-axis (s) }\end{array}$ & $\begin{array}{l}\text { Motion } \\
\text { time of } \\
\text { Y-axis (s) }\end{array}$ & $\begin{array}{l}\text { Motion } \\
\text { time of } \\
\text { Z-axis (s) }\end{array}$ & $\begin{array}{l}\text { Machining } \\
\text { time (s) }\end{array}$ \\
\hline Radial & 74.10 & 73.95 & 91.73 & 163.44 \\
Scan line & 63.72 & 62.68 & 75.14 & 159.75 \\
Contour line & 98.76 & 98.45 & 8.68 & 161.98 \\
\hline
\end{tabular}

correctly simulate the power consumption during acceleration motion and the standby power consumption for each axis as shown in Fig. 12c.

However, the magnitudes of the results obtained through simulation and measurement for each tool path followed the same relation, e.g., in each case, the total energy consumption was the highest for the radial path and lowest for the scan line path. Therefore, the energy consumption of the motion for the tool 
paths can be qualitatively evaluated by the proposed model.

From the results as shown in Fig. 13, the energy consumption for the radial tool path, which requires the longest motion time of each axis, was the highest. In addition, the total energy consumption of the Y-axis was approximately $500 \mathrm{~J}$ higher than that of the X-axis. In the case of the contour line tool path, the energy consumption for the Z-axis was extremely low. However, the total energy consumption for the contour line tool path was higher than that for the scan line tool path. Because, the machining time of Y-axis for the scan line was the shortest in all tool paths. Thus, the scan line tool path resulted in the lowest energy consumption among the tool paths considered herein. Moreover, the energy consumption for the Y-axis was found to greatly influence the energy consumption required for the machine tool motion.

As the results, it can be said that we can reduce the total energy consumption for machining process from the point of the relationships between the power consumption and the motion time of each axis.

\section{Conclusions}

In this paper, the simulation model of the power consumption of the feed drive system in a machine tool was developed. Based on the proposed model, the power consumption of the motion during machining process was simulated for three tool paths. In addition, the power consumption was measured experimentally, and the simulation and measurement results were compared, revealing that the proposed model can qualitatively evaluate the energy consumption of the motion for a machine tool. The influence of the axis requiring the greatest power consumption and the machining time for each axis was revealed.

The ultimate goal of this study is to develop a tool path generation system which takes into consideration the energy consumption for the motion of NC machine tools based on the proposed model and this result. Furthermore, we will investigate the influence of the cutting force to the energy consumption and it will be considered in the proposed model.

\section{References}

[1] Draganescu, F., Gheorghe, M., and Doicin, C. V. 2003. "Models of Machine Tool Efficiency and Specific Consumed Energy.” Journal of Materials Processing Technology 141 (1): 9-15.

[2] Neugebauer, R., Wabner, M., Rentzsch, H., and Ihlenfeldt, S. 2011. "Structure Principles of Energy Efficient Machine Tools.” CIRP Journal of Manufacturing Science and Technology 4 (2): 136-47.

[3] Lee, J. Y., Shin, Y. J., Kim, M. S., Kim, E. S., Yoon, H. S., Kim, S. Y., Yoon, Y. C., Ahn, S. H., and Min, S. 2016. “A Simplified Machine-Tool Power-Consumption Measurement Procedure and Methodology for Estimating Total Energy Consumption.” Journal of Manufacturing Science and Engineering 138 (5): 051004-1-9.

[4] Gotze, U., Koriath, H. J., Kolesnikov, A., Lindner, R., and Paetzold, J. 2012. "Integrated Methodology for the Evaluation of the Energy- and Cost-Effectiveness of Machine Tools.” CIRP Journal of Manufacturing Science and Technology 5 (3): 151-63.

[5] Mori, M., Fujishima, M., Inamasu, Y., and Oda, Y. 2011. "A Study on Energy Efficiency Improvement for Machine Tools.” CIRP Annals-Manufacturing Technology 60 (1): 145-8.

[6] Avram, O. I., and Xirouchakis, P. 2011. "Evaluating the Use Phase Energy Requirements of a Machine Tool System.” International Journal of Cleaner Production 19 (6-7): 699-711.

[7] Campatelli, G., Scippa, A., Lorenzini, L., and Sato, R. 2015. "Optimal Workpiece Orientation to Reduce the Energy Consumption of a Milling Process.” Journal of Precision Engineering and Manufacturing-Green Technology 2 (1): 5-13.

[8] Akio, H., Ryuta, S., and Keiichi, S. 2014. "Measurement and Simulation of Energy Consumption of Feed Drive Systems." International Journal of Mechanics Engineering and Automation 4 (3): 203-12.

[9] Sato, R., and Tsutsumi, M. 2005. "Modeling and Controller Tuning Techniques for Feed Drive Systems." In Proceedings of the ASME DSC-Vol. 74-1, 669-79. 